\title{
Single-port laparoscopic percutaneous extraperitoneal closure of femoral hernia in children and adolescents: case series
}

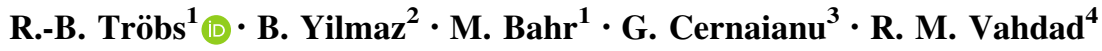

Received: 30 July 2016/ Accepted: 5 January 2017/Published online: 14 February 2017

(c) The Author(s) 2017. This article is published with open access at Springerlink.com

\begin{abstract}
Background Femoral hernias are an often unexpected groin pathology during childhood. However, the pediatric surgeon has to be aware to diagnose femoral hernia and to repair this condition. This is the first report on laparoscopic percutaneous extraperitoneal closure of femoral hernia (LPEF) in children and adolescents.

Methods Over a 6-year period in a bi-institutional clinical study, we retrospectively identified six children and one young adult who underwent LPEF repair.

Results Femoral hernia was laparoscopically confirmed in seven patients. Ages at surgery were 3, 5, 7, 7, 8, 8.5, and 18 years, respectively. In the first case, we combined
\end{abstract}

R.-B. Tröbs

ralf-bodo.troebs@elisabethgruppe.de

B. Yilmaz

memo55@gmx.de

M. Bahr

micha.bahr@elisabethgruppe.de

G. Cernaianu

grigorec@hotmail.com

R. M. Vahdad

rvahdad@aol.com

1 Department of Pediatric Surgery, Marienhospital Herne, St. Elisabeth-Group, Ruhr-University of Bochum, Widumer Strasse 8, 44627 Herne, Germany

2 Clinic for Surgery and Pediatric Surgery, Friedrich-EbertStraße 13, 33602 Bielefeld, Germany

3 Department of General, Visceral and Tumor Surgery, University of Cologne, Kerpener Str. 26, 50937 Cologne, Germany

4 Department of Pediatric Surgery and Pediatric Urology, Klinikum der Stadt Köln, Amsterdamer Str. 59, 50735 Cologne, Germany laparoscopic diagnosis with open repair. In the consecutive six cases, hernias were repaired minimally invasively with the percutaneous extraperitoneal technique described below. During a follow-up between 6 years and 6 months, no recurrence was observed.

Surgical technique For LPEF, we percutaneously placed a peritoneal U-shape suture with integrated transfixation of the hernia sac, closed with an epifascial knot. We performed LPEF using two graspers. The peritoneum was percutaneously punctured with a venous cannula through which the suture was inserted. One grasper was inserted through the working channel of the laparoscope to invert the hernia sac into the abdominal cavity. A mini-grasping forceps inserted through the cannula retrieved the thread and completed LPEF.

Conclusion We demonstrate that single-port laparoscopic percutaneous extraperitoneal closure of femoral hernia is successful and quick in children and in adolescents.

Keywords Femoral hernia $\cdot$ Pediatric $\cdot$ Laparoscopic closure

\section{Introduction}

Femoral hernias are a very infrequent occurrence among pediatric patients. In the pre-laparoscopic era, misinterpretation as inguinal hernia was frequent and led to unnecessary attempts for inguinal hernia repair $[1,2]$. This situation changed completely with introduction of the laparoscopy for pediatric hernia repair [3]. Careful laparoscopic inspection of the suspicious regions easily allows the identification of the underlying type of hernia. Under the point of view achieved by laparoscopy, femoral hernias were "those that opened medially to the femoral 
vessels and below the inguinal ligament". For the treatment of a femoral hernia, different techniques of laparoscopic closure have been reported in the literature [4-9].

Herein, we report our experience with an innovative single-port laparoscopic percutaneous extraperitoneal closure (LPEC) of femoral hernia. In our departments, LPEC technique is mainly used for the repair of inguinal hernias in girls.

\section{Material and method}

We retrospectively identified in a bi-institutional clinical study six children and one young woman $(n=7)$, who underwent femoral hernia repair between June 2009 and June 2015. In a further case, the assumed femoral hernia was not confirmed.

We recorded sex, age at presentation, intraoperative findings, skin-to-skin operative times, complications, and follow-up. A total of 2800 children underwent inguinal hernia repair during the study period. The diagnosis of inguinocrural hernias was predominately made by careful clinical examination. Ultrasonographic investigations were only applied in the case of inconsistent presentation.

\section{Surgical method}

Laparoscopic percutaneous extraperitoneal closure of femoral hernia (LPEF) is achieved by means of a percutaneously placed peritoneal U-shape suture with integrated transfixation of the hernia sac (Fig. 1).

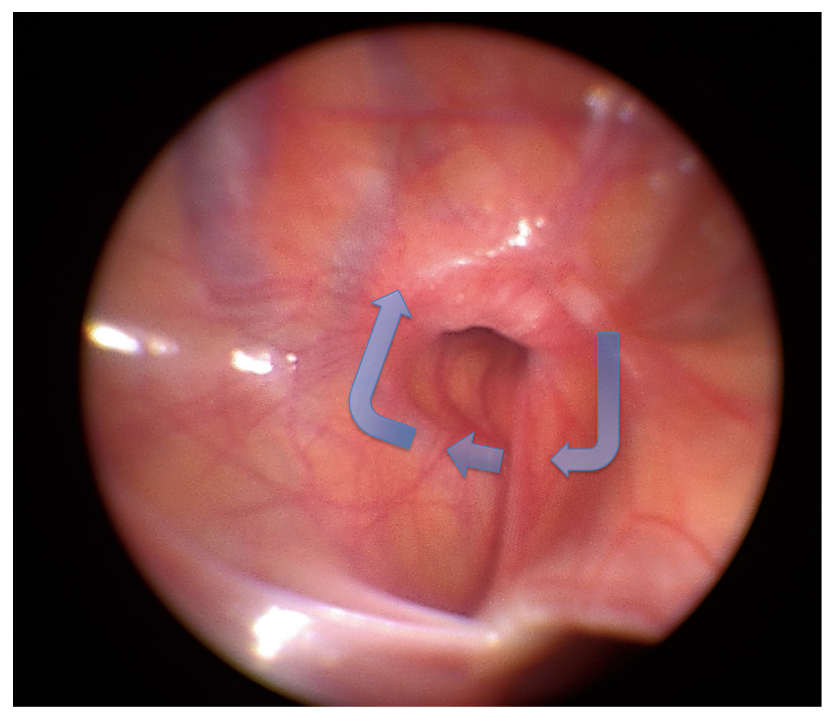

Fig. 1 Laparoscopic view on a left sided femoral hernia. Arrows show the internal course of the U-shape suture
In detail, we introduce either a $12^{\circ}, 4.5-\mathrm{mm}$ compact hysteroscope with $2.33-\mathrm{mm}$ working channel (Olympus Surgical Technologies Europe, Hamburg, Germany), or a $0^{\circ}$, 5.5-mm mini-operating laparoscope with $3.5-\mathrm{mm}$ working channel (Richard Wolf GmbH, Knittlingen, Germany) through a single infraumbilical access, as previously described [10], to identify the femoral region.

Subsequently, the peritoneal cavity is percutaneously punctured medially with a $14-\mathrm{G}$ peripheral venous cannula (Vasofix safety ${ }^{\circledR} 2.2 \times 50 \mathrm{~mm}$; Braun Melsungen AG, Melsungen, Germany) (Fig. 2). Peritoneum around the femoral ring is uploaded as much as possible (Fig. 1). The hernia sac is inverted into the abdominal cavity by means of a forceps inserted through the working channel of the laparoscope and punctured with the cannula to achieve transfixation. A $2 \times 0$ non-absorbable braided polyester suture is pushed into the abdominal cavity and grasped. After removal of this cannula, a puncture from opposite is performed, and the suture is grasped through the cannula shaft using small flexible urological foreign body forceps (3 Ch/230 mm; Richard Wolf GmbH, Knittlingen, Germany) and externalized. The suture is then extracorporeally knotted, burying the knot epifascially at the level of the inguinal ligament. For insertion of the cannula, the suture material, and knot, tying a single 2-mm puncture wound of the skin is sufficient. This closes the hernia by lifting up the encircled peritoneum of the femoral ring. If possible, the medial umbilical ligament was included into the suture to enhance mechanical stability (Fig. 3).

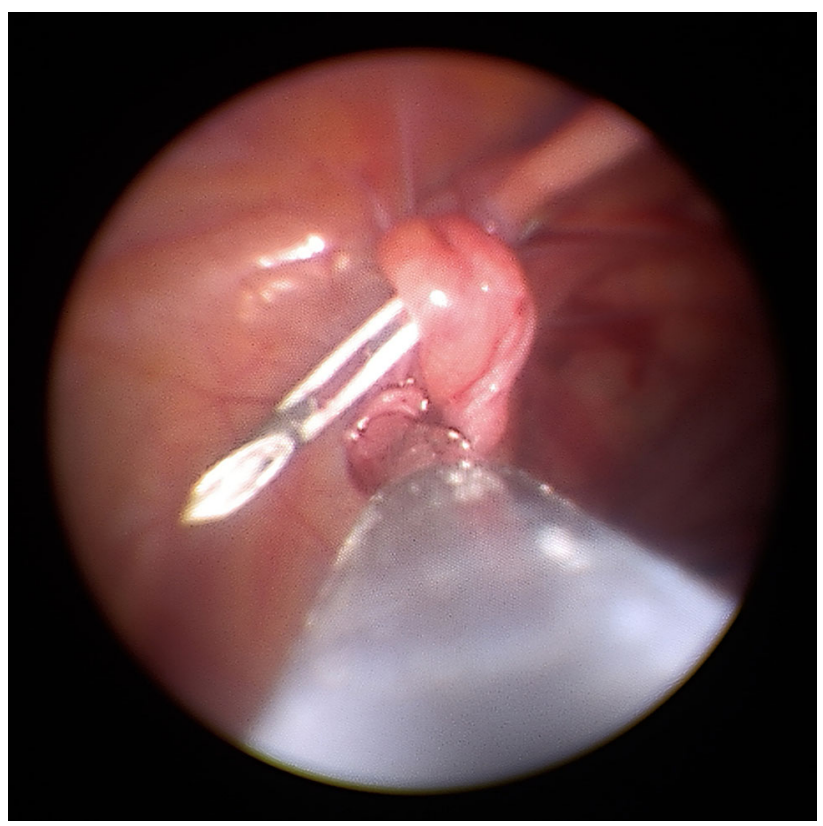

Fig. 2 Transfixation of the inverted hernia sack with the venous cannula is performed 


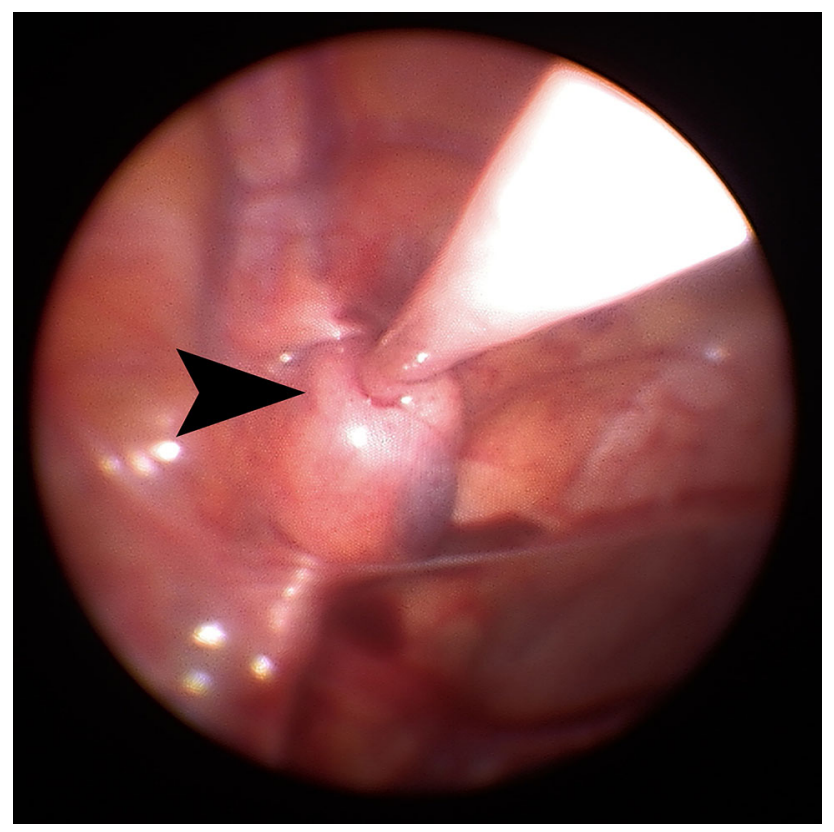

Fig. 3 Suture is extracorporeally tied. The femoral ring is closed and medial umbilical ligament serves as enforcement

\section{Results}

In our series, four of seven cases were diagnosed preoperatively by one experienced surgeon (BY), and in three cases, the diagnosis was established incidentally. In the four cases with assumed femoral, hernia was confirmed with ultrasonography. Demographic data and details of our patients are provided in Table 1 .

In an eighth case (female, 20 years), a femoral hernia was assumed by clinical examination; however, endoscopy revealed unilateral presence of a combination of indirect and direct inguinal hernia (hernia en pantaloon) that was closed with LPEC [3]. The clinical appearance of the hernia en pantaloon was misleading and no ultrasound examination was performed. This patient was excluded from the further study. Laparoscopic exploration of the contralateral side in all cases did not reveal any further inguinal pathology. History of the previous ipsilateral inguinal hernia repair was reported in one child.

In our first case, the presence of a femoral hernia was confirmed by laparoscopy; however, we converted to open repair under laparoscopic guidance. In the consecutive cases, femoral hernia was identified laparoscopically, and repair was performed minimally invasively, as described above. All patients underwent at least one follow-up examination. All patientś legal guardians were very satisfied with the postoperative cosmetic appearance. During a postoperative observation period between 6 years and 6 months, no recurrence was observed.

\section{Discussion}

A femoral hernia is defined as the protrusion of the abdominal contents through the annulus femoralis to the fossa ovalis [2]. This type of hernia had been described the first time by Franz Caspar Hesselbach in 1798 [11]. The anatomical concept of the myopectineal orifice of Fruchaud gives a modern anatomical explanation on the occurrence of both inguinal and femoral hernias $[12,13]$. The diagnosis of femoral hernia is made by careful clinical examination. Clinically, a soft and non-tender bulge is seen and felt in projection on the femoral trigon. Ultrasound examination may confirm the diagnosis and it can visualize the content of the hernia sack. Incarcerations of the omentum and bowel may occur $[14,15]$. In children, the rate of preoperative misdiagnosis has been reported in more than three-thirds of cases $[2,8,15,16]$.

Femoral hernias are rare. In a meta-analysis of three large studies on pediatric femoral hernia, the relative incidence of femoral hernia was 39 cases out of a total of 12,126 inguinal hernia repairs $(0.32 \%)[14,17,18]$. Our incidence during the study period was lower with seven cases of a total of 2800 inguinal hernia patients $(0.25 \%)$. One study found a ratio of $1.1 \%$ in a highly selected cohort [3]. In our departments, inguinal hernia repair in girls is predominately performed by laparoscopy. In selected cases, laparoscopy is provided for male hernias. Contradictory to our results ( 5 girls, 2 boys), exclusively male patients were reported in another single institution series [3]. According to larger cohorts, the age at presentation with femoral hernia varied between 6 weeks and 15 years, and there was a slight female predominance (1.2-fold more females) $[14,17,18]$. In a Japanese report, the sex ratio of 3:2 showed a more pronounced female prevalence [15].

It is thought that femoral hernias are predominately acquired conditions, and there is never a preformed congenital peritoneal sac. The vast majority of femoral hernias are unilateral; however, bilateral cases may occur [14-17]. Anatomical variations in individuals can predispose to the development of femoral hernia in the presence of acquired predisposing factors. In adults, multiparous and obese women aged over 50 years are predominately affected [19]. In the presented series, no patient suffered from predisposing etiological factors like chronic pulmonary disease or obesity, and only one girl had the previous inguinal hernia repair during the early childhood. It has been reported that recurrences after open inguinal hernia repair often present as femoral hernias $[4,16,18]$.

Surgery of femoral hernia is based on anatomy. The femoral ring is defined as the small opening between the pectineal ligament touchdown of the iliopubic tract and transversalis fascia and the external iliac vein [13]. The 
Table 1 Demographic data, operation times, and time span of follow-up

\begin{tabular}{llllllll}
\hline Case & Gender & Age & Side & Content & Repair & Operative time & Follow-up (years) \\
\hline 1 & Female & 8 & Left & Empty & Scopy + open repair & 65 min & 5 \\
2 & Female & 7 & Left & Empty & Laparoscopic herniorrhaphy & 38 min & 1 \\
3 & Female & $8,5 / 12$ & Left & Empty & Laparoscopic herniorrhaphy & $35 \mathrm{~min}$ & 1 \\
4 & Female & 18 & Left & Greater omentum & Laparoscopic herniorrhaphy & $58 \mathrm{~min}$ & 0.5 \\
5 & Female & $3,6 / 12$ & Right & Empty & Laparoscopic herniorrhaphy & $11 \mathrm{~min}$ & 5 \\
6 & Male & $5,9 / 12$ & Left & Empty & Laparoscopic herniorrhaphy & $35 \mathrm{~min}$ & 6 \\
7 & Male & $7,3 / 12$ & Left & Empty & Laparoscopic herniorrhaphy & $38 \mathrm{~min}$ & 6 \\
\hline
\end{tabular}

Table 2 Pediatric series of laparoscopic femoral hernia repair, techniques, and results

\begin{tabular}{|c|c|c|c|c|c|c|}
\hline Reference & $\begin{array}{l}\text { Number of } \\
\text { patients }\end{array}$ & $\begin{array}{l}\text { Trocars } \\
\text { applied }\end{array}$ & Techniques & Plug/alloplastic material & $\begin{array}{l}\text { Follow-up } \\
\text { (months) }\end{array}$ & $\begin{array}{l}\text { Number of } \\
\text { recurrences }\end{array}$ \\
\hline Lee et al. [4] & 4 & 3 & Hybrid & Teflon $^{\circledR}$ patch/plug & $6-24$ & No \\
\hline Ikossi et al. [5] & 1 & 3 & Laparoscopic intracorporeal & Umbilical ligament & 24 & No \\
\hline Adibe et al. [6] & 3 & 3 & Hybrid & No & 6 & No \\
\hline Mathyssen et al. [7] & 10 & 3 & Laparoscopic & No & $8-89$ & No \\
\hline Wright $[8]$ & 3 & & Different techniques & Mesh plug $(\mathrm{n}=1)$ & Not given & No \\
\hline Tan et al. [9] & 3 & 1 & Hybrid & Polypropylene mesh cigarette & 6 & No \\
\hline Presented series & 4 & 1 & Laparoscopic extracorporeal & No & $6-72$ & No \\
\hline
\end{tabular}

boundaries of the femoral ring are anterior, the inguinal ligament; posterior the pectineus fascia and underlying muscle; lateral the external iliac/femoral vein; and medial the iliopectineal (Cooper's) and the lacunar (Gimbernat's) ligament.

Techniques of open femoral hernia repair in childhood can performed via the supra-inguinal or the infra-inguinal approach. At open inguinal hernia repair, the femoral ring can be visualized by incision through the inguinal canal and the transversalis fascia with subsequent high ligation or inversion of the hernia and closure of the femoral ring $[14,17,20]$. For narrowing the femoral ring, Cooper's ligament was sutured to the inguinal ligament. The classical technique according to McVay uses a transversalis fascia pedicle flap to close the femoral canal. To facilitate the open infra-inguinal closure, identification and liberation of the hernia sac can be supported by laparoscopic transillumination.

It has been demonstrated that laparoscopy allows an objective view of the anatomy of unusual hernias of the internal inguinal region in infants and children [3]. For laparoscopic repair, different techniques were applied. In general, intracorporeal or alternatively extracorporeal percutaneous methods can be performed [21]. It has been reported that simple hernia sac ligation alone may be not sufficient for a long lasting repair. Laparoscopic exposure and closure of the defect by incorporation of subperitoneal fascial tissue into the suture was successful in one series
[3]. Different techniques with or without the use of patches or plugs were reported to prevent relapses. Laparoscopic identification and assistance in combination with a small infranguinal incision (hybrid technique) was predominately reported in the laparoscopic literature [4, 6, 9]. Some authors propose the use of alloplastic non-absorbable prosthetic material even in children [4, 8, 9, 22]. According to our philosophy, we avoid the use of non-absorbable mesh plugs or patches. Foreign body reaction, irritation and erosion of surrounding tissues, and a lifelong persistence of non-absorbable tissue may carry incalculable risks. In one single case report, the umbilical ligament was applied as a plug for laparoscopic repair, different techniques were applied (Table 2) [5].

Our technique is based on the transfixation of the inverted hernia sac, which is lifted up together with the encircled femoral ring. This maneuver allows the mechanical stable closure of the hernia. This technique is a modified and anatomically adapted version of the method proposed by Endo et al. for pediatric inguinal hernia repair [23]. The procedure is not technically demanding and standard operating room equipment is used. The single use venous safety cannula always allows a smooth passage of the abdominal wall. An additional infraumbilical incision was avoided in the last six patients. With only one umbilical wound and the nearly invisible inguinal puncture, the cosmetic outcomes were excellent. 
Our study has several potential limitations. The number of patients is small and the length of follow-up is short. The neighborhood of the external iliac vessels requires a meticulous technique to avoid narrowing of the vein and bleeding.

Despite these potential limitations, the authors are convinced that laparoscopic groin exploration and femoral hernia repair in children and adolescents is a safe alternative to open repair. However, we agree with the statement of Puri et al.: "no surgeon has enough experience to prefer one particular technique above another" [16].

In conclusion, we present an easy to do single-port percutaneous technique for femoral hernia repair in children and adolescents. Transfixation of the inverted sac, uplifting of the closed femoral ring to the inguinal ligament, and incorporation of the umbilical ligament are the main principles of this technique. The authors advocate LPEC for the repair of pediatric and adolescent femoral hernias.

\section{Compliance with ethical standards}

Conflict of interest RBT, BY, GC, and RMV declare no conflict of interest. MB declares conflict of interest not directly related to the submitted work.

Ethical approval All procedures performed in studies involving human participants were in accordance with the ethical standards of the institutional and/or national research committee and with the 1964 Helsinki declaration and its later amendments or comparable ethical standards.

Informed consent Informed consent was obtained from all individual participant included in the study.

Open Access This article is distributed under the terms of the Creative Commons Attribution-NonCommercial 4.0 International License (http://creativecommons.org/licenses/by-nc/4.0/), which permits any noncommercial use, distribution, and reproduction in any medium, provided you give appropriate credit to the original author(s) and the source, provide a link to the Creative Commons license, and indicate if changes were made.

\section{References}

1. Chapman WH, Barcia PJ (1991) Femoral hernia in children: an infrequent problem revisited. Mil Med 156:631-633

2. Temiz A, Akcora B, Temiz M, Canbolant E (2008) A rare and unrecognized pathology in children: femoral hernia. Hernia 12:553-556

3. Schier F, Klizaite J (2004) Rare inguinal hernia forms in children. Pediatr Surg Int 20:748-752
4. Lee SL, DuBois JJ (2000) Laparoscopic diagnosis and repair of pediatric femoral hernia. Initial experience of four cases. Surg Endosc 14:1110-1113

5. Ikossi DG, Shaheen R, Mallory B (2005) Laparoscopic femoral hernia repair using umbilical ligament as plug. J Laparoendosc Adv Surg Techn A 15:197-200

6. Adibe OO, Hansen EN, Seifarth FG, Burnweit CA, Muensterer OJ (2009) Laparoscopic-assisted repair of femoral hernias in children. J Laparoendosc Adv Tech A 19:691-694. doi:10.1089/ lap.2009.0134

7. Mathyssens LEM, Philippe P (2009) A new minimally invasive technique for the repair of femoral hernia in children. About 13 laparoscopic repairs in 10 patients. J Pediatr Surg 44:967-971

8. Wright MF, Scollay JM, McCabe AJ, Munro FD (2011) Paediatric femoral hernia-the diagnostic challenge. Int $\mathrm{J}$ Surg 9:472-474

9. Tan SY, Stevens MJ, Mueller CM (2013) A novel laparoscopicassisted approach to the repair of pediatric femoral hernias. J Laparoendosc Adv Surg Techn 23:946-948

10. Tröbs RB, Vahdad MR, Cernaianu G (2016) Transumbilical cord access (TUCA) for laparoscopy in infants and children: simple, safe and fast. Surg Today 46(2):235-240

11. Agarwal AK, Mukherjee R (2008) Franz Kaspar Hesselbach (1759-1816). Indian J Surg 70:96-98

12. Colborn GL, Skandalakis JE (1998) Laparoscopic inguinal anatomy. Hernia 2:179-191

13. Skandalakis JE, Colborn GL, Skandalakis LJ (1997) The embryology of the inguinofemoral area: an overview. Hernia $1: 45-54$

14. Fonkalsrud EW, deLorimier AA (1965) Femoral and direct inguinal hernias in infants and children. JAMA 192:101-103

15. Asai A, Takehara H, Okada A, Masamune K, Komi N (1992) A case of femoral hernia in a child. Tokushima $J$ Exp Med 39:145-147

16. De Caluwe D, Chertin B, Puri P (2003) Childhood femoral hernia; a commonly misdiagnose condition. Ped Surg Int 19:608-609

17. Marshall DG (1983) Femoral hernias in children. J Pediatr Surg 18:160-162

18. Al-Shanafey S, Giacomantonio M (1999) Femoral hernia in children. J Pediatr Sug 34:1104-1106

19. Kochupapy RT, Ranganathan G, Dias S, Shanahan D (2013) Aetiology of femoral hernias revisited: bilateral femoral hernia in a young male (two cases). Ann R Coll Surg Engl 15:e14-e16

20. Haberlink A, Sauer H (1990) Treatment of femoral hernia in children. Chirurg 61:289-291

21. Ostlie DJ, Ponsky TA (2014) Technical options of the laparoscopic pediatric inguinal hernia repair. J Laparoendosc Adv Surg Techn 24:194-198

22. Ceran C, Koylouglo G, Sonmez K (2002) Femoral hernia repair with mesh plug in children. J Pediatr Surg 37:1456-1458

23. Endo M, Watanabe T, Nakano M, Yoshida F, Ukiyama E (2009) Laparoscopic completely extraperitoneal repair of inguinal hernia in children: a single institution experience with 1,257 repairs compared with cut-down herniorrhaphy. Surg Endosc 23:1706-1712 